\title{
Optical performance of finished and unfinished tropical timbers exposed to ultraviolet light in the field in Costa Rica
}

\section{Cynthia Salas, Róger Moya \& Lupita Vargas-Fonseca}

To cite this article: Cynthia Salas, Róger Moya \& Lupita Vargas-Fonseca (2016) Optical performance of finished and unfinished tropical timbers exposed to ultraviolet light in the field in Costa Rica, Wood Material Science \& Engineering, 11:2, 62-78, DOI: 10.1080/17480272.2014.949855

To link to this article: https://doi.org/10.1080/17480272.2014.949855

\section{曲 Published online: 22 Aug 2014.}

\section{Submit your article to this journal $\llbracket$}

Џll Article views: 77

Q View related articles $\square$

View Crossmark data ¿

4 Citing articles: 3 View citing articles 


\title{
Optical performance of finished and unfinished tropical timbers exposed to ultraviolet light in the field in Costa Rica
}

\author{
CYNTHIA SALAS, RÓGER MOYA, \& LUPITA VARGAS-FONSECA \\ Instituto Tecnológico de Costa Rica, Escuela de Ingeniería Forestal, Cartago, Costa Rica
}

\begin{abstract}
This study evaluated wood color change $\left(\Delta E^{\star}\right)$ and the surface quality in 10 tropical wood species painted with three finishes (composed of wax and polyurethane). Two weathering conditions were tested: natural weathering (NW) and artificial weathering (AW). The results showed that the application of these finishes, decreased the luminosity $\left(L^{\star}\right)$, increased the redness $\left(a^{\star}\right)$ and the yellowness $\left(b^{\star}\right)$ parameters in all species. $\Delta E^{\star}$, after weathering exposure, was affected significantly by $L^{\star}, a^{\star}$, and $b$, whereas for finished or pretreated wood, $L^{\star}$ and $b^{\star}$ are the main parameters affecting $\Delta E^{\star}$ in the 10 tropical species studied. $\Delta E^{\star}$ values found in different finishes and pretreatments are cataloged as total change of color. Other important results were that tropical light colored timber with natural pretreatment produced higher $\Delta E^{\star}$ than dark colored timber. The stains and fungal development were observed in polyurethane finishes in NW, but not in AW. The irregular and mosaic flaws were not observed in any kind of finish or pretreatment of surface. The values of the quality index created, which considered long and short lines and switch flaws, were lowest in NW and in waxy finish, while the highest value was obtained with the polyurethane finish.
\end{abstract}

Keywords: Lab color systems, color change, surface quality, tropical wood, finishing, coating

\section{Introduction}

The environmental conditions of tropical regions, such as high temperature and rainfall throughout the year, as happens in Costa Rica, enable the development of a great variety of forest plantation timber species (Petit and Montagnini 2004). Many of these species have been successfully planted with commercial purposes (Nichols and Vanclay 2012); however, according to Moya and Muñoz (2010), the lack of knowledge about their wood properties or processing, as well as color change of the finish applied on them, has been an obstacle to their utilization. Studies have been initiated recently on the physical and mechanical properties (Moya and Muñoz 2010), their performance during the drying process (Moya et al. 2013), and also on the caloric properties (Moya and Tenorio 2013) of these species.

On the other hand, tropical timber species have gained importance in the marketing of wood-finishing products (chemical products), formulated to protect the color and quality of the wood surface (Deka et al.
2008). However, these products had been formulated for wood obtained from trees grown under natural conditions. Tropical timber is characterized by high quantity and a variety of wood extractives (Pandey 2005a), which provide resistance to high temperature conditions, the perpendicular incidence of ultraviolet (UV) radiation, and high precipitation levels (Pastore et al. 2004). Meanwhile, timber plantations do not have the same resistance. Plantation woods usually have lower resistance values and lower content of extractives than wood from trees growing under natural conditions (Zobel and Sprague 1998).

There are two large paint factories in Costa Rica (http://www.pinturassur.com/ and http://www.grupo kativo.com/), and other smaller ones that produce finishes and pretreatments for wood. Such products are distributed and used from Mexico to Panama, where tropical species coming from forest plantations are currently used.

These paint factories have developed finishes for the tropical region, to protect the wood from the

Correspondence: Róger Moya, Instituto Tecnológico de Costa Rica, Escuela de Ingeniería Forestal, P.O. Box 159-7050 Cartago, Costa Rica. Tel: (506) 2550 9092. Fax: (506) 2550 3315. E-mail: rmoya@itcr.ac.cr 
intensity of the UV rays, the high relative humidity, and the high levels of precipitation. The polyurethane type finishes stand out for the protection of wood from outdoor conditions. These are organic compounds of the urethane prepolymer component, water insoluble, and UV light refractive, in order to reduce weather effects and maintain the quality of wood color (Williams 2005). As for oil finishes, they can be dissolved in water, offer UV ray protection, and are water repellent, thus preventing damage to the wood surface (Williams 2005).

The finished wood surface is degraded (color changes and degradation), when exposed weather effects (Schnabel et al. 2009). Factors such as solar radiation, temperature, rain, wind, relative humidity, heat, pollution, and others accelerate the process of discoloration and deterioration of the finish (Schaller and Rogez 2007, Deka et al. 2008). Various studies (Schaller and Rogez 2007, Deka et al. 2008, Ahajji et al. 2009) have found that UV light, visible light, and infrared light generate most chemical reactions in the wood components and in the finish itself.

The studies on the deterioration of wood surface finishes usually focus on temperate wood species (Petric et al. 2004, Deka et al. 2008, Ahaji et al. 2009). Due to this orientation, many factories use wood species from temperate climates to establish the characteristics of the finish they produce. In fact, Costa Rican factories use Pinus radiata as a standard for studies on the performance of wood finish. However, there are few studies on the performance of finish for tropical woods, such as Cedrela odorata, Carapa guianenesis, Tectona grandis, and Acacia mangium (Valverde and Moya 2014). The performance of various finishes in natural weathering (NW) and artificial weathering (AW) conditions were studied in these species.

In view of this situation, it is important to understand the behavior of color and the degradation of surface finishes on wood from fast growing plantations - with different treatments and exposed to weathering conditions (natural or artificial) - in order to determine the possible uses and markets for those species, with the convenient finish. Therefore, the present research studies the initial color change when applying 3 different types of pretreatment and finishes formulated for tropical conditions to 10 species growing under plantation conditions. Also, the present work defines the color change and deterioration of these different finishes for each of these 10 plantation species when exposed to AW and NW conditions.

\section{Materials and methods}

Site, plantation description, and tree sampling

Ten different pure plantations located in several parts of Costa Rica were studied (Figure 2). The plantation species were A. mangium, Alnus acuminata, Bombacopsis quinata, Cupressus lusitanica, Gmelina arborea, Pinus caribaea, Swietenia macrophylla, T. grandis, Terminalia amazonia, and Terminalia oblonga. The initial planting density was 1111 trees/ ha $(3 \times 3 \mathrm{~m}$ spacing). At the time of evaluation, the age was 9-18 years old and the density was of 495-575 trees/ha. The samples for the finishing trials were extracted from $25-\mathrm{mm}$ thick boards dried to $12 \%$ moisture content in conventional kilns; for further information see Moya et al. (2013). All these species are being introduced in the production of outdoor furniture. Twelve boards were used in each species.

\section{Sampling}

A total of 104 units of $15 \times 7.5 \times 0.6 \mathrm{~cm}$ were extracted from the 12 dried boards per species. These samples were conditioned at $12 \%$ moisture content $\left(22{ }^{\circ} \mathrm{C}\right.$ temperature and $67 \%$ relative humidity) for 4 weeks before the application of the different finishes and pretreatment. Then all finishes and pretreatment were applied. In total 4 units were tested in each treatment, which means a total of 104 samples per species ( 3 finishes $\times 4$ surface treatments $\times 4$ units +1 control test $\times 4$ units). The samples selected were free from damages and flaws and only heartwood board was only considered.

\section{Surface preparation and application of finishes and pretreatment}

Conditioned samples were sanded with sandpaper $\# 80$ and subsequently with \#120 and \#220. Three types of outdoor finishing were used (Table I), selected from those widely used in Costa Rica. Before the application of the three types of finishes, the surface of the wood was prepared with four different pretreatments also used in the tropics (Table I). Therefore, 12 different treatments were applied to each species. All species were compared with control test that corresponded to wood surface without pretreatment or the application of finishing (Figure 1). After applying to the surface of the wood sample, the ends, edges and bottom surface of the sample were sealed with polyurethane. 
Table I. Finishes studied and coating utilized on the surface of 10 tropical species wood from plantations.

\begin{tabular}{|c|c|c|}
\hline Type & Products & Description \\
\hline \multirow[t]{4}{*}{ Finishes } & A & $\begin{array}{l}\text { Water base, fast dry, protects against damage caused by moisture, and ultraviolet rays, and provides } \\
\text { a mildew-resistant finish that would not crack, peel, or flake. The finishes were applied with a } \\
\text { spreading rate of } 3.7 \mathrm{~m}^{2} / 1 \text {. Color: cedar, nonvolatile content: } 45 \% \text {, and application method: brush }\end{array}$ \\
\hline & B & $\begin{array}{l}\text { One component polyurethane (urethane prepolymer) finish for one step application on exterior. } \\
\text { The finish was applied with a spreading rate of } 14.7 \mathrm{~m}^{2} / 1 \text {. Color: clear gloss, nonvolatile content: } \\
50 \% \text {, and application method: spray }\end{array}$ \\
\hline & $\mathrm{C}$ & $\begin{array}{l}\text { One component polyurethane (urethane prepolymer) finish for one step application on exterior. } \\
\text { The finish was applied with a spreading rate of } 14.7 \mathrm{~m}^{2} / 1 \text {. Color: clear satin, nonvolatile content: } \\
50 \% \text {, and application method: spray }\end{array}$ \\
\hline & Unfinished or control & The surface was left as it is \\
\hline \multirow[t]{4}{*}{ Pretreatment } & Wax & $\begin{array}{l}\text { Natural oil modified for exterior condition. It protects against insects, fungal decay, and UV } \\
\text { radiation. Color: clear, nonvolatile content: } 80 \% \text {, and application method: flannel }\end{array}$ \\
\hline & Preservative & $\begin{array}{l}\text { Water base, no color, no odor, protects against insects, fungus and rot fungus. Color: clear, } \\
\text { nonvolatile content: } 80 \% \text {, arsenic as active component, and application method: brush }\end{array}$ \\
\hline & Wax-preservative & $\begin{array}{l}\text { Preservative was added on the wood surface and the wax was added after } 24 \text { hours. Color: clear, } \\
\text { nonvolatile content: } 80 \% \text {, and application method: brush-flannel }\end{array}$ \\
\hline & Untreated & Finishes were applied without any previous treatments on wood surface \\
\hline
\end{tabular}

\section{Weathering exposure characteristics}

In this study, two kinds of exposure were tested: NW and AW. In NW, wood samples are exposed for 500 days with an inclination of $15^{\circ}$ south in an area free of shade and where the rain, sun, and wind impacted directly upon the samples. The test began in June 2011. Wood samples were exposed in the Cartago province of Costa Rica $\left(9^{\circ} 50^{\prime} 59^{\prime \prime} \mathrm{N}\right.$; 83 $84^{\circ} 37^{\prime \prime} \mathrm{W}$ ) (Figure 2). The site has an altitude of 1380 m.a.s.l. with an annual temperature between 15.0 and $23.9^{\circ} \mathrm{C}$ and an average precipitation of $1563.5 \mathrm{~mm}$. The solar radiation in Cartago is $17 \mathrm{MJ} / \mathrm{m}^{2}$. The climatic conditions were widely detailed by Valverde and Moya (2014). For the AW, UV exposure was administered by means of a weathering Q-Lab camera (QUV/spray model). The ASTM G-154

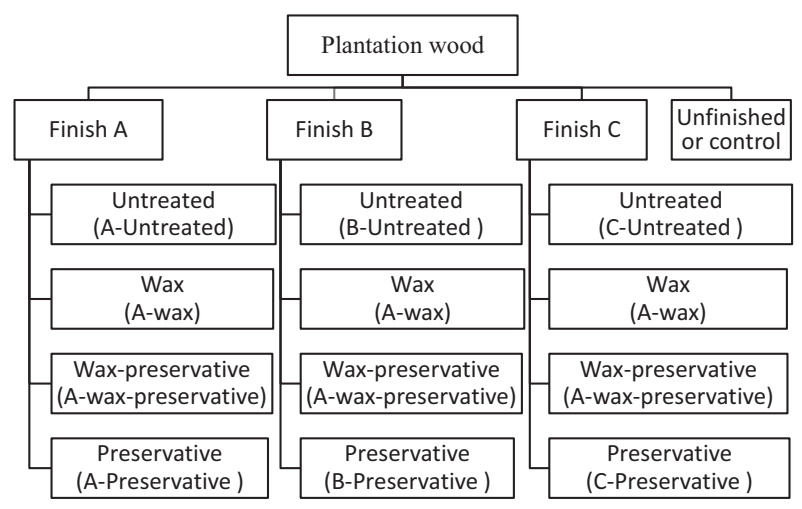

Figure 1. Finishes and pretreatment applied on the surface of 10 tropical species wood from plantations.

Note: Name in parenthesis represents the abbreviation utilized in the study. standard was applied for this test (ASTM 2013a). The exposure consisted of 4-hour cycles in two phases: first, 4 hours of UV radiation at $50{ }^{\circ} \mathrm{C}$ and $0.71 \mathrm{~W} / \mathrm{m}^{2}$ (with mercury bulb type UVB $313 \mathrm{~L}$ and wavelength $310 \mathrm{~nm}$ ), then a second phase of condensation that took 2 hours and consisted of using evaporated water at $50{ }^{\circ} \mathrm{C}$. The total exposure amounted to 400 hours for each species.

\section{Color determination}

This wood characteristic was measured before and after weathering exposure on the finishes' surface. This means that the surface color was measured on all samples of NW immediately after pretreatment application. Meanwhile, the surface colors of all samples of AW were measured before weathering began. Next, a lapse of time between pretreatment application and color measuring was presented in these samples. Color measuring was done with a Hunter Lab mini Scan XE Plus spectrophotometer. The CIE Lab standardized chromatologic system was used. The range of this measurement is from 400 to $700 \mathrm{~nm}$ with an opening at the point of measurement of $11 \mathrm{~mm}$. For the observation of reflection, the specular component was included at a $10^{\circ}$ angle, which is normal for the specimen surface (D65/10); a field of vision of $2^{\circ}$ (Standard observer, CIE 1931); and an illumination standard of D65 (corresponding to daylight in $6500 \mathrm{~K}$ ). The mini Scan XE Plus generated three parameters for each measurement, namely, $L^{\star}$ (luminosity), $a^{\star}$ (redness), and finally $b^{\star}$ (yellowness). The color was measured at room temperature in two different measurements, 

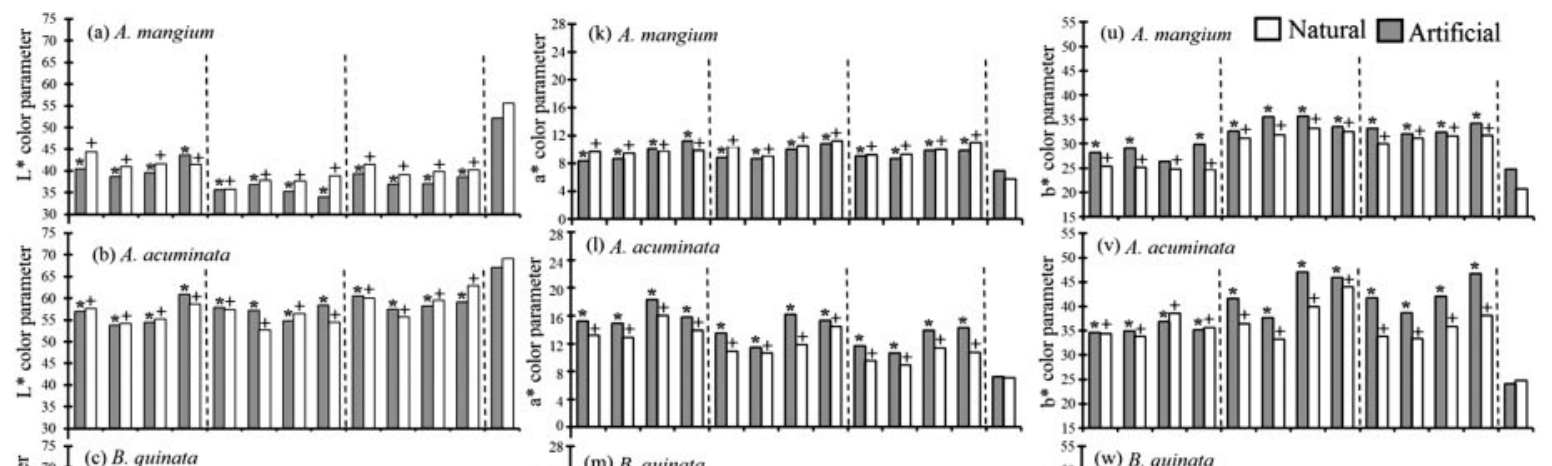

${ }^{75} \mathrm{I}$ (c) B. quinata

焉 70
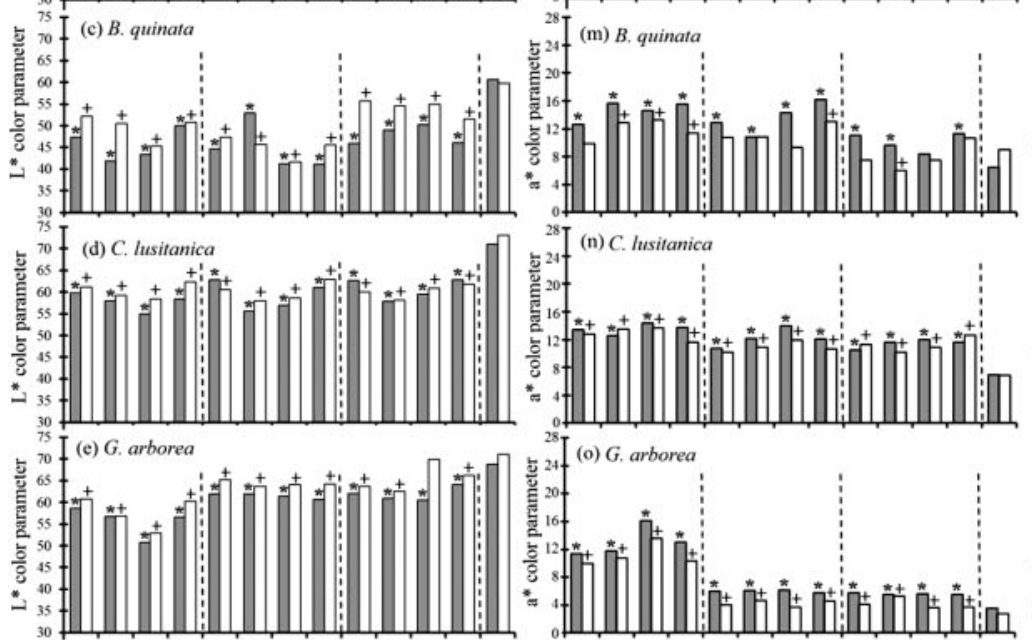

${ }_{24}^{28}$ (o) G. arborea
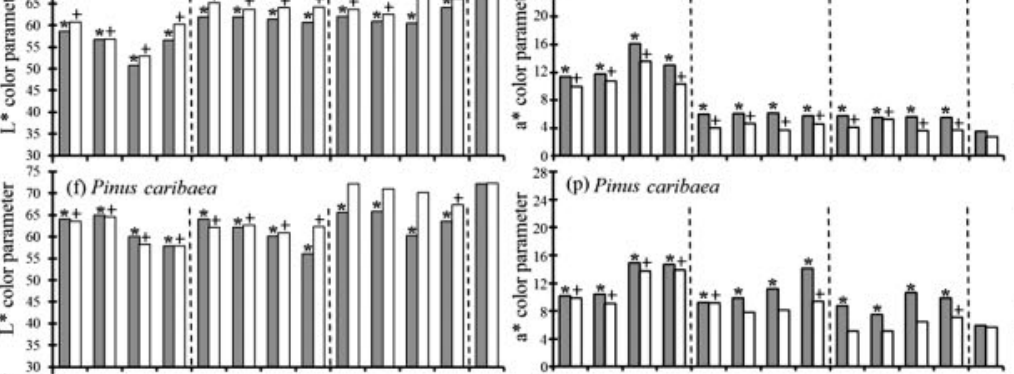

${ }^{55} \mathrm{I} f$ (w) B. quinata

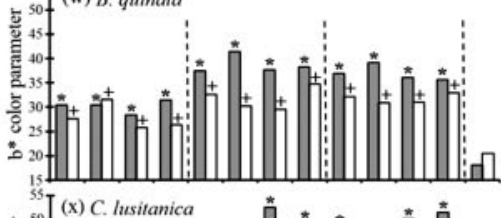

75 (g) S. macrophylla
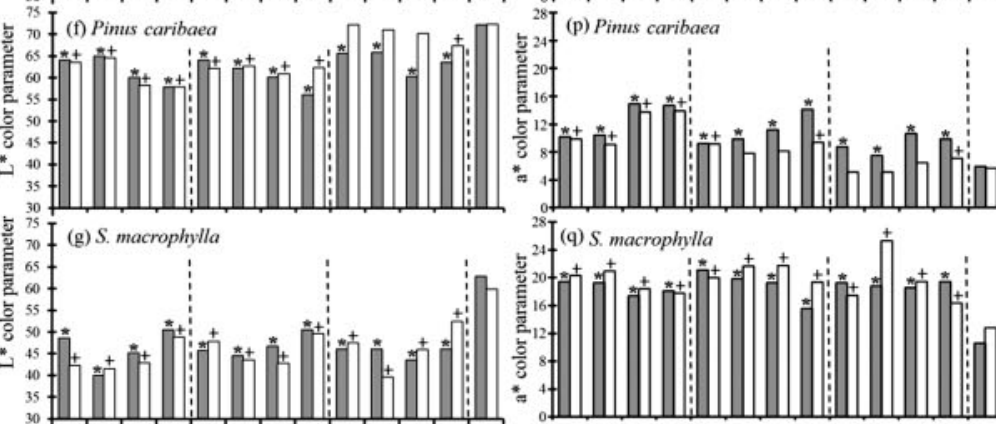

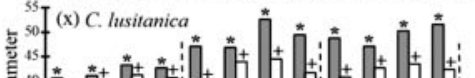

$70 \mathrm{I}$ (h) $T$. grandis
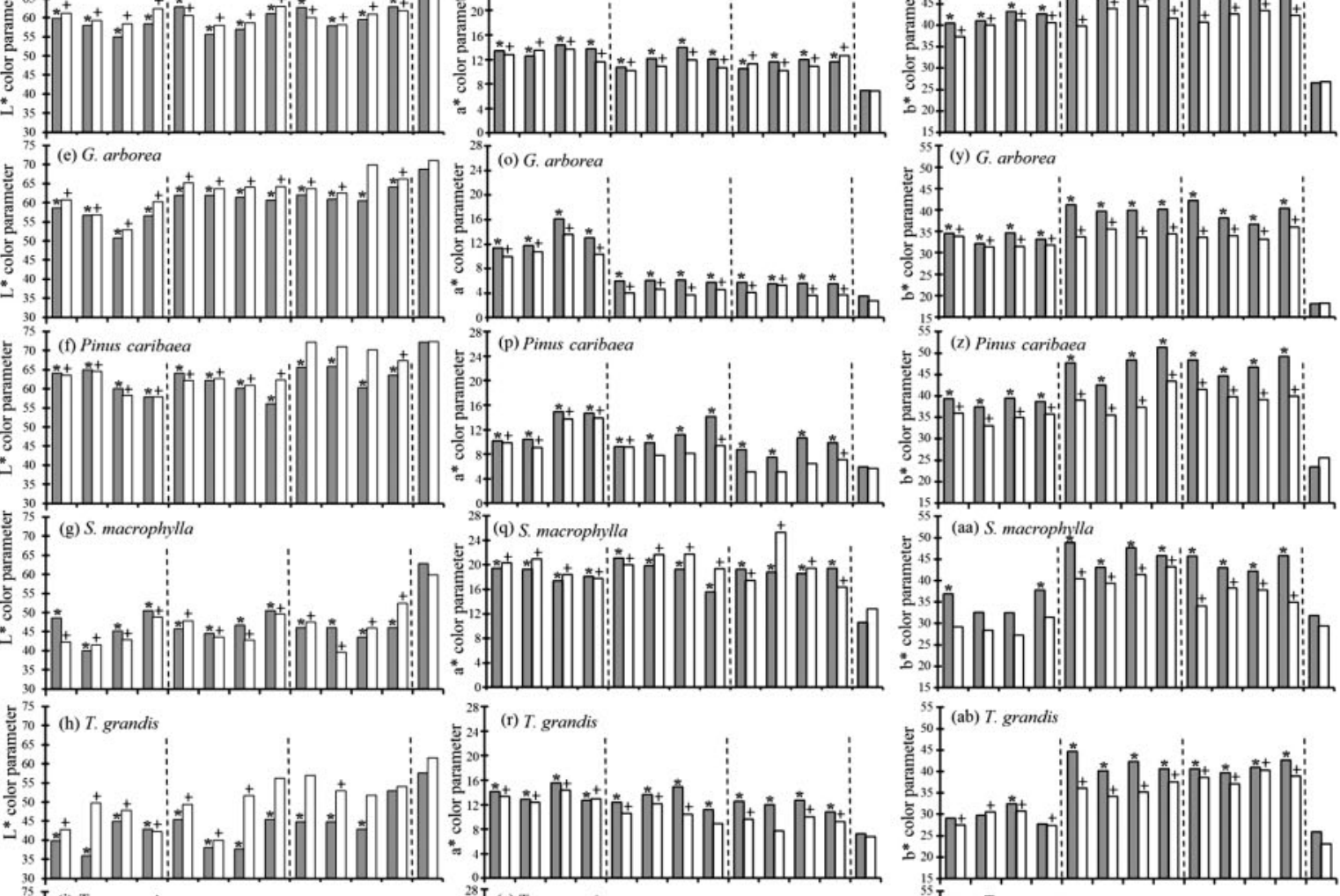

${ }^{55} \mathrm{I}$ (y) G. arborea
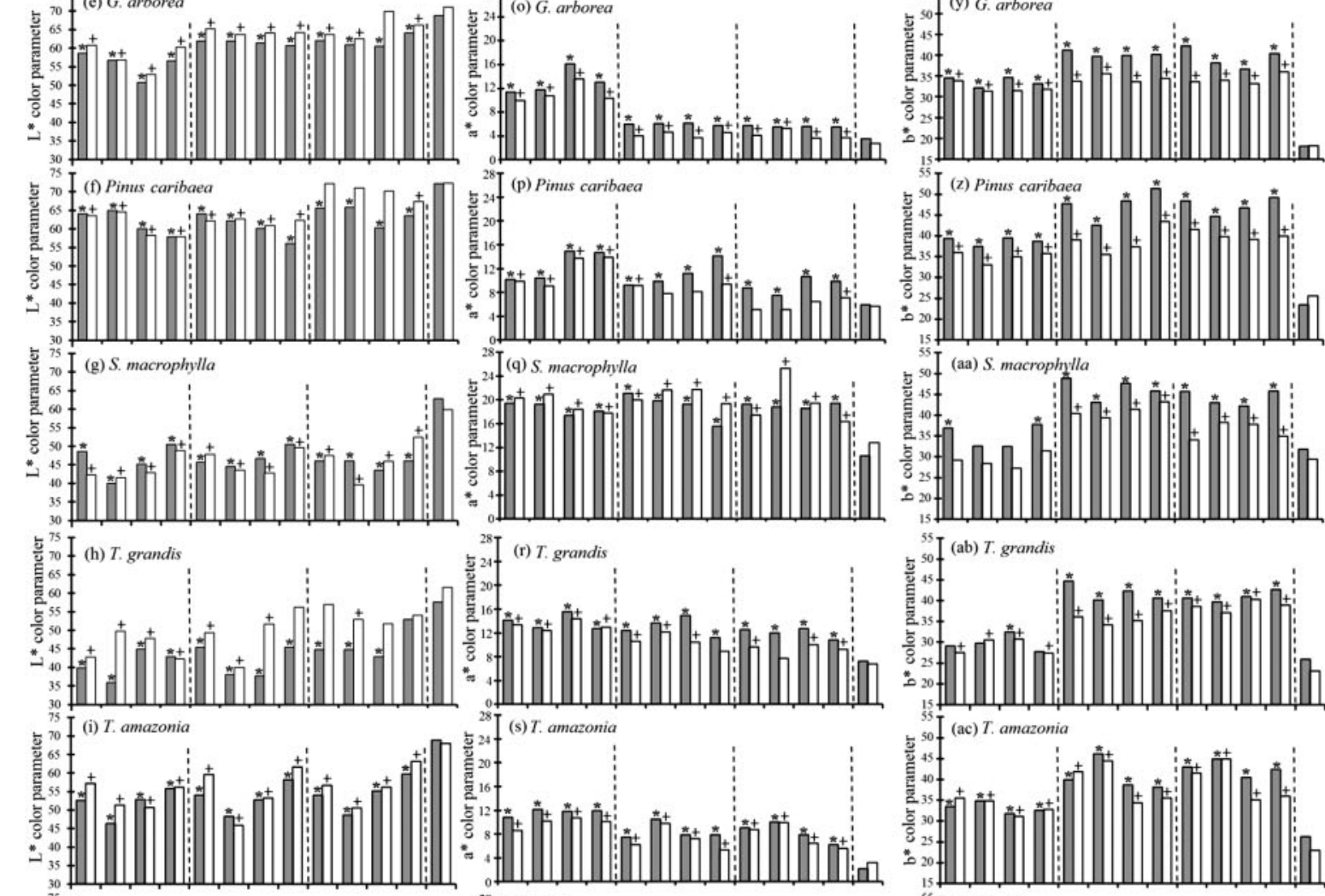

${ }^{28} \mathrm{I}$ (r) T. grandis
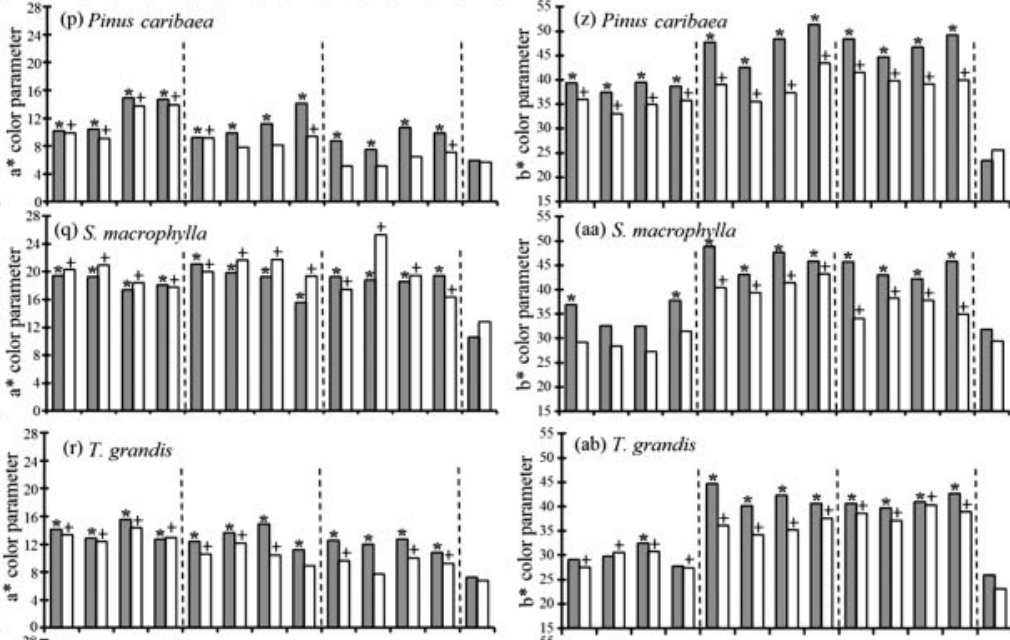

${ }_{70}^{75}$ (j) $T$. oblonge ${ }^{28}$ (s) T. amazonia

24

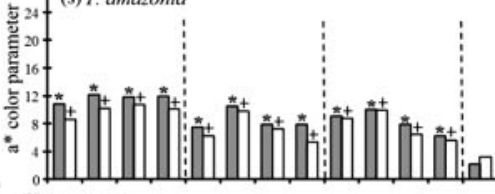

${ }_{50}^{55}$ (ab) T. grandis
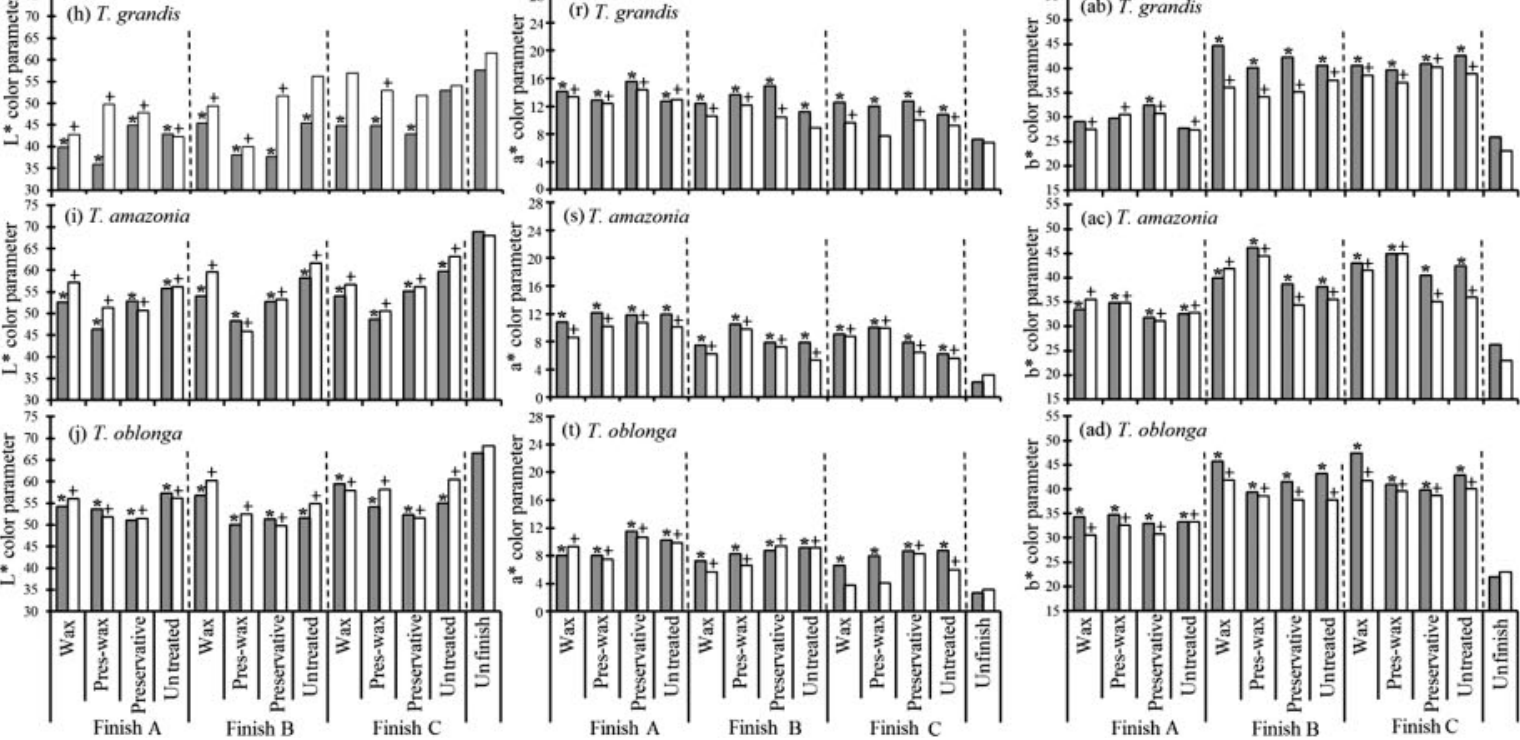

${ }^{28} \mathrm{~T}$ (t) T. oblonga
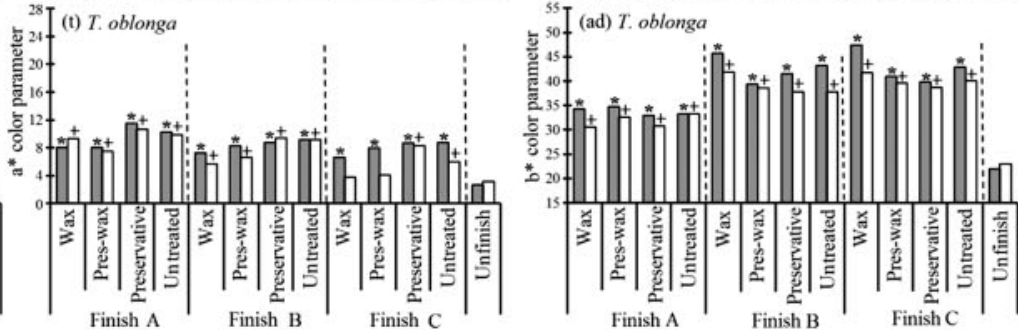

Figure 2. Initial values for the color parameters $L^{\star}, a^{\star}$, and $b^{\star}$ of the wood of 10 plantation species in Costa Rica, with 3 finishes and different surface treatments.

Note: ${ }^{\star}$ statistical difference $($ Valor- $P<0.05)$ between unfinished treatment and different combination of finish and surface treatment for AW + statistical difference $($ Valor- $P<0.05$ ) between unfinished treatment and different combination of finish and surface treatment for NW. 
each one at $2 \mathrm{~cm}$ from the ends. The measurement of color was evaluated in the UV radiation phase to avoid measurement errors due to the condensation in AW. Wood samples in NW were evaluated between the 10th and 12th hour in the morning and without any event of rain before the measurement.

\section{Color change $\left(\Delta \mathrm{E}^{\star}\right)$}

It was determined by three conditions: (i) color difference between unfinished and finishing treatment in each wood species, (ii) color difference between untreated surface and pretreatment in each finish and each species, and (iii) color change for each finish between, after, and before weathering exposure. These differences were determined according to the ASTM D 2244 standard (ASTM 2013b) whose formula is detailed in Equation 1 (ASTM 2013b). To catalog the $\Delta E^{\star}$ color variation, Cui et al's (2004) method was used. It establishes five color change levels perceived by the human eye: if $0<\Delta E^{\star}>0.5$ the color change is not perceived by the human eye; if $1.5<\Delta E^{\star}>3.0$ the color change is barely perceived; if $3.0<\Delta E^{\star}>6.0$ the change is perceived; if $6.0<\Delta E^{\star}>12.0$ the color change is quite noticeable by the human eye, and finally, if $\Delta E^{\star}$ is higher than 12 , then a total color change occurred:

$$
\Delta E^{*}=\sqrt{(\Delta L)^{2}+(\Delta a)^{2}+(\Delta b)^{2}}
$$

where $\Delta E^{\star}$ is the wood color difference, $\Delta L$ the $L^{\star}$ before weathering $-L^{\star}$ after weathering, $\Delta a$ the $a^{\star}$ before weathering $-a^{\star}$ after weathering, and $\Delta b$ the $b^{\star}$ before weathering $-b^{\star}$ after weathering.

\section{Evaluation of the quality of finish}

After NW or AW exposures, fungi, stains, or bubbles on finished surface were evaluated. Fungi and stain were evaluated according to their presence or absence, by means of visual inspections: for fungi, presence of fruiting body or spores; for stain, surface color different than the typical color of surface coating after 500 exposures (NW or AW), the presence or absence of fungi, stains, or bubbles on finished surface were evaluated. Fungi and stain presence were evaluated by the presence or absence. Both defects were observed by visual inspections: for fungi presence, fruiting body or spores presence was observed, and for stain, surface color different than typical color of surface coating was observed. The presence of bubbles is evidenced as cracks of the finish coat on the wood surface. In addition, for the evaluation of the quality of finish in each species and their behavior to weathering (NW as well as AW) the ASTM D-660 standard (ASTM 2013c) was used, that establishes an evaluation for the different kinds of deterioration that finishes face: irregular, long line, short parallels, mosaic, and switch. In general, deterioration is evaluated on an even scale from 2 to 10 , in which, as the number approaches 2 it means a greater deterioration of the finish.

\section{Statistical analysis}

First, the differences between the control test and each finishing treatment and pretreatment were evaluated. A one-factor (one-way-Anova) analysis of variance per species was applied to finish color parameters. The model included the following sources of variation: finishing $(f)$, pretreatment $(c)$, the interactions between weathering and pretreatment (Equation 2). The difference among the averages was assessed through Dunnett's test with a level of significance of $P<0.05$, where the control treatment consists of wood samples without any finishing or pretreatment. Also, the influence of the change in color parameters $\left(\Delta L^{\star}, \Delta a^{\star} y \Delta b^{\star}\right)$ on total color change $\left(\mathrm{A} E^{\star}\right)$ was evaluated using multiple regression analysis (Equation 3) on the wooden surface with different finishes. Each parameter change in the regression was assessed using a significance level of $99 \%$ :

$$
\begin{gathered}
Y_{i j}=\mu+f_{i}+c_{j}+f^{*} c_{i j}+e_{i j} \\
\Delta E^{*}=\Delta L+\Delta a+\Delta b+e_{i j}
\end{gathered}
$$

where $Y_{i j}$ is the single observation of each color parameter of the $i j$-wood sample, $\mu$ is the overall mean, $f$ is the $i$ th-finishing type fixed effect, $c$ is $j$ th-pretreatment fixed effect, $f^{\star} c_{i j}$ is the random interaction between the $i$ th finishing type and the $j$ th pretreatment, and $e_{i j}$ is the residual random effect.

Regarding the quality of finishes with different pretreatments, first, the presence or absence of fungus, stains, or bubbles were expressed as the percentage of presence in relation to total samples of finishing and pretreatment. Second, the quality index of degradation (surface quality index, SQI) was developed, that considers the five types of flaws evaluated under the ASTM D-660 standard (ASTM 2013c); namely, irregularities, long lines, short parallels, switch, and mosaic. The weighting considered the importance of the appearance of flaws, the surface with long lines being the one with the highest weighting $(50 \%)$, and then short lines $(25 \%)$, switch surface $(15 \%)$, and finally, irregular surface $(10 \%)$. The mosaic flaw was not considered in this index because this flaw was not observed in any 
sample. Subsequently, SQI behavior was evaluated with exposure time in NW and AW using the following equation:

$$
\begin{aligned}
S Q I= & (I R \times 0.10)+(L L \times 0.50)+(S P \times 0.25) \\
& +(S S \times 0.15)
\end{aligned}
$$

where $I R$ is the irregular flaw, $L L$ the long line flaw, $S P$ the short parallel flaw, and $S S$ the switch flaw.

\section{Results}

\section{Initial surface color of wood}

$L^{\star}$ parameter was above 35 , varying from 35 to 70 ; the $a^{\star}$ parameter was positive in all cases, varying from 9 to 24 , and the $b^{\star}$ parameter was also positive, varying from 15 to 50 (Figure 2). A. mangium, $S$. macrophylla, and $T$. grandis registered the lowest values in $L^{\star}$ parameter (Figure $2 \mathrm{a}, 2 \mathrm{~g}$, and $2 \mathrm{~h}$ ), whereas the rest of the species presented average values higher than those for the previous species. Regarding the $a^{\star}$ parameter, the lowest values were for G. arborea, $P$. caribaea, and the two Terminalia species (Figure 2o, 2p, 2s, and 2t). On the other hand, S. macrophylla presented the highest values (Figure $2 \mathrm{q}$ ). Last, the $b^{\star}$ parameter show no differentiation among the various species (Figure $2 \mathrm{u}-1 \mathrm{ad}$ ).

The application of the different types of finish or pretreatments affects the wood color parameters, in all wood species. The $L^{\star}$ values decreased with the application of finish in all species and in both types of weathering, except $G$. arborea (Figure 2e), $P$. caribaea (Figure 2f), and T. grandis (Figure $2 \mathrm{~h}$ ) in some finishes, with some treatments, with finish C. Meanwhile, the $a^{\star}$ values increased with the application of finishes to the wood, except in some treatments of $B$. quinata, $P$. caribaea, $T$. oblonga, and $T$. grandis (Figure $2 \mathrm{~m}, 2 \mathrm{p}, 2 \mathrm{r}$, and $2 \mathrm{t}$ ), where statistical differences were not observed. Concerning the $b^{\star}$ parameter, it was found that this value increased in almost of the species and conditions, except in $S$. macrophylla (Figure 2aa).

In relation to the values obtained for the color change $\left(\Delta E^{\star}\right)$ in the two types of weathering, the values varied from 10.9 to 31.1 (Table II). A. mangium showed the lowest $\Delta E^{\star}$ and the highest values were found in B. quinata and P. caribaea (Table II). Intermediate values were found in $C$. lusitanica, G. arborea, P. caribaea, T. grandis, T. amazonia, T. oblonga, A. acuminata, and S. macrophylla. On the other hand, $\Delta E^{\star}$ values for all of the species were in general lower for the wood with finish $\mathrm{A}$, followed by finishes $\mathrm{C}$ and $\mathrm{B}$, with few differences among them (Table II). Moreover, almost color changes $\left(\Delta E^{\star}\right)$ occurred in AW, using the three types of finishes for all species.

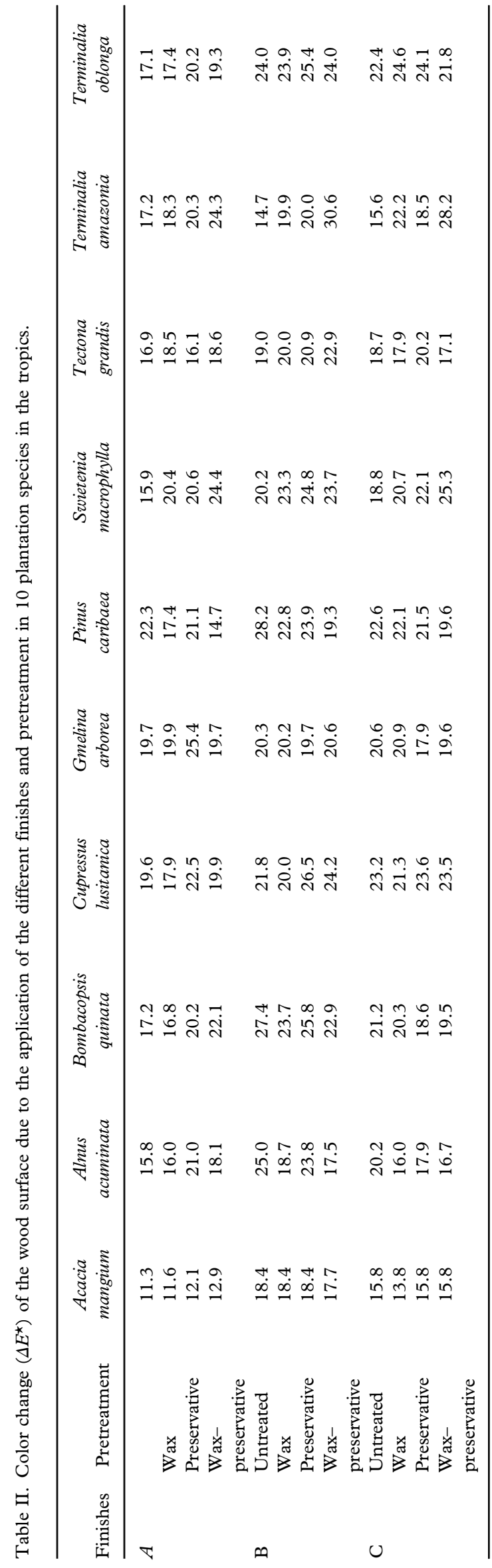


Color change due to exposure

As expected, the highest change in all types of finishes and surface treatments for all species was in the samples exposed to NW. Similarly, $\Delta E^{\star}$ values were higher than 12 for all species and types of finishes with NW exposure (Figure 3).

The highest surface color changes, given by high values of $\Delta E^{\star}$, were observed in $A$. acuminata, C. lusitanica, G. arborea, P. caribaea, S. macrophylla, and the two Terminalia species (Figure 3b, 3d-3g, 3i, and $3 \mathrm{j}$ ) in NW. A. mangium, B. quinata, and $T$. grandis (Figure $3 \mathrm{a}, 3 \mathrm{c}$, and $3 \mathrm{~h}$ ), on the other hand, presented the lowest $\Delta E^{\star}$ in NW. For AW, the highest $\Delta E^{\star}$ values, above 12 , were found in $S$. macrophylla (Figure 3g), followed by C. lusitanica with $\Delta E^{\star}$ values close to 12 (Figure 3d). T. amazonia presented values lower than 12 in the A-wax and A-preservative treatments, $\mathrm{A}$ and $\mathrm{B}$ without treatment, and the control test (Figure 3i). Some treatments with values over 12 were also observed in
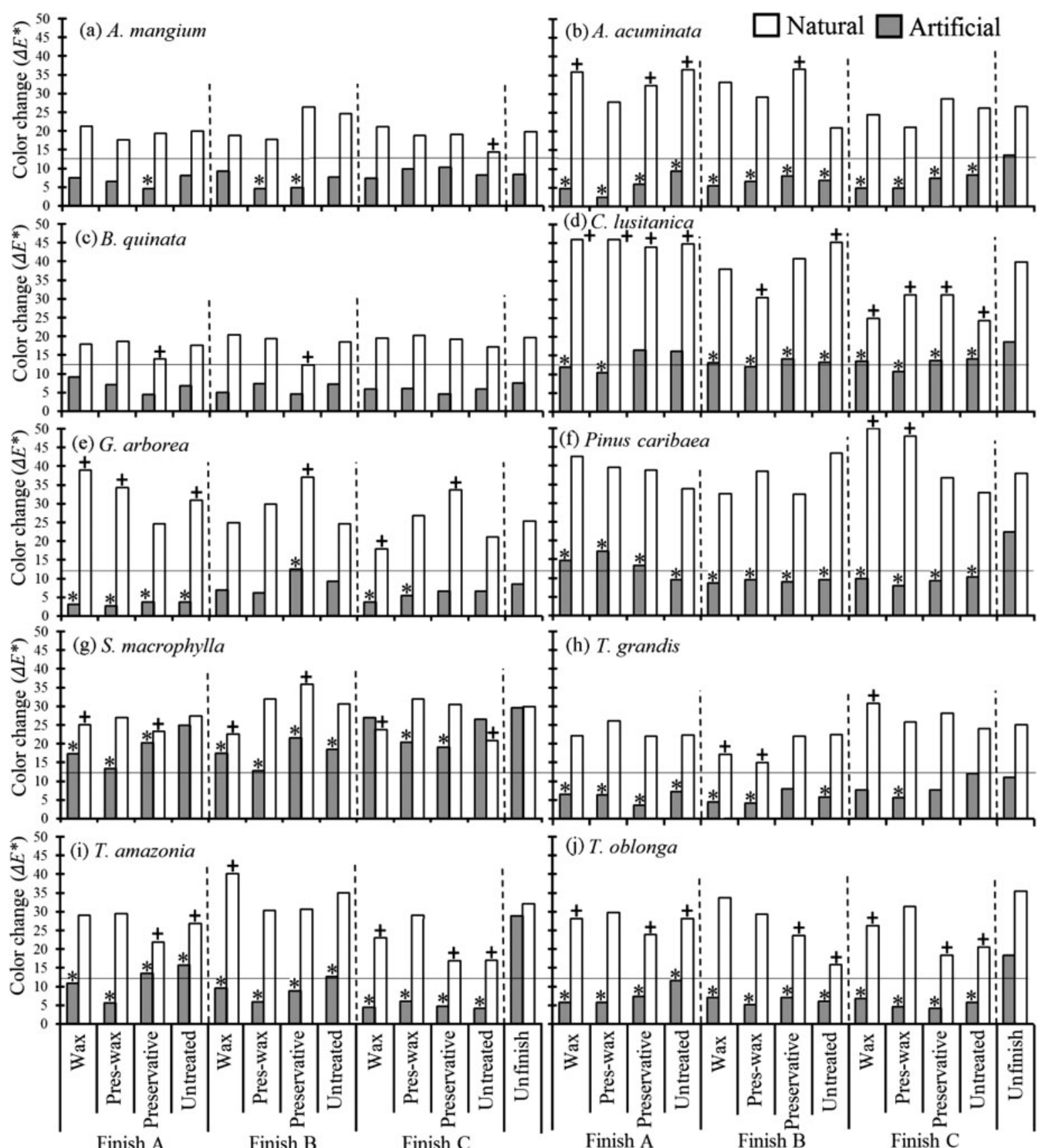

Figure 3. Color change $\left(\Delta E^{\star}\right)$ values of 3 types of finishing exposed to NW and AW in 10 wood types from forest plantations. Note: ${ }^{\star}$ statistical difference (Valor- $P<0.05$ ) between unfinished treatment and different combination of finish and surface treatment for AW + statistical difference (Valor $-P<0.05$ ) between unfinished treatment and different combination of finish and surface treatment for NW. 
P. caribaea, specifically with finish A and the control sample (Figure 3f). T. grandis and T. oblonga presented values lower than 12 in almost treatments except the control sample (Figure $3 \mathrm{~h}$ and $3 \mathrm{j}$ ). Last, A. mangium, $A$. acuminata, B. quinata, and $G$. melina presented $\Delta E^{\star}$ values under 12 in all treatments (Figure $3 \mathrm{a}-3 \mathrm{c}$ and $3 \mathrm{e}$ ).

Concerning the $\Delta E^{\star}$ of the different types of finishing $(\mathrm{A}-\mathrm{C})$ and the pretreatments applied (wax, preservative-wax, preservative), compared to the control sample after exposure to weathering conditions, AW was found to produce the highest quantity of statistical differences among the species (Figure 3), except for B. quinata which showed no differences (Figure $3 \mathrm{c}$ ), and $A$. mangium and G. arborea (Figure 3a and 3e), which presented few differences with the control sample. Regarding NW, it depended on the species, coating, or surface treatment. For $A$. mangium, a lower $\Delta E^{\star}$ was only found in the C-untreated treatment (Figure 2a), while $P$. caribea presented $\Delta E^{\star}$ values for C-wax and C-preservative that were higher than for the control (Figure 3f). Other species (A. acuminata, B. quinata, C. lusitanica, G. arborea, S. macrophylla, T. grandis, T. amazonia, and T. oblonga) presented greater variation between treatment or coating (Figure $3 b-3 j)$.

The $\Delta E^{\star}$ of the surface of the finish after weathering was influenced by the color parameters. The analysis of this influence by means of a multiple regression (Equation 3), showed the following (Table III):

1. For the control sample (without finish), the $\Delta E^{\star}$ was significantly affected by the luminosity $\left(L^{\star}\right)$, redness $\left(a^{\star}\right)$, and yellowness $\left(b^{\star}\right)$ in the 10 species and in the two types of weathering, except for $A$. mangium, $T$. grandis, and $G$. arborea, showing that some treatments were not affected by these three color parameters.

2. The $L^{\star}$ parameter significantly affected $\Delta E^{\star}$ in most treatments.

3. The $\Delta E^{\star}$ value was significantly affected by $L^{\star}$ and $b^{\star}$ together in many of the species and types of finish, for example, in T. amazonia, with finishes $\mathrm{B}$ and $\mathrm{C}$.

4. In those cases where the luminosity parameter $\left(L^{\star}\right)$ did not affect the $\Delta E^{\star}$, the $b^{\star}$ parameter did. For example, in the C-wax treatment for A. mangium, S. macrophylla, T. grandis, and T. amazonia.

5. The cases in which the $L^{\star}$ parameter was the only parameter to affect $\Delta E^{\star}$, were mostly in AW (22 out of 25). A. magnium did not present such situation.

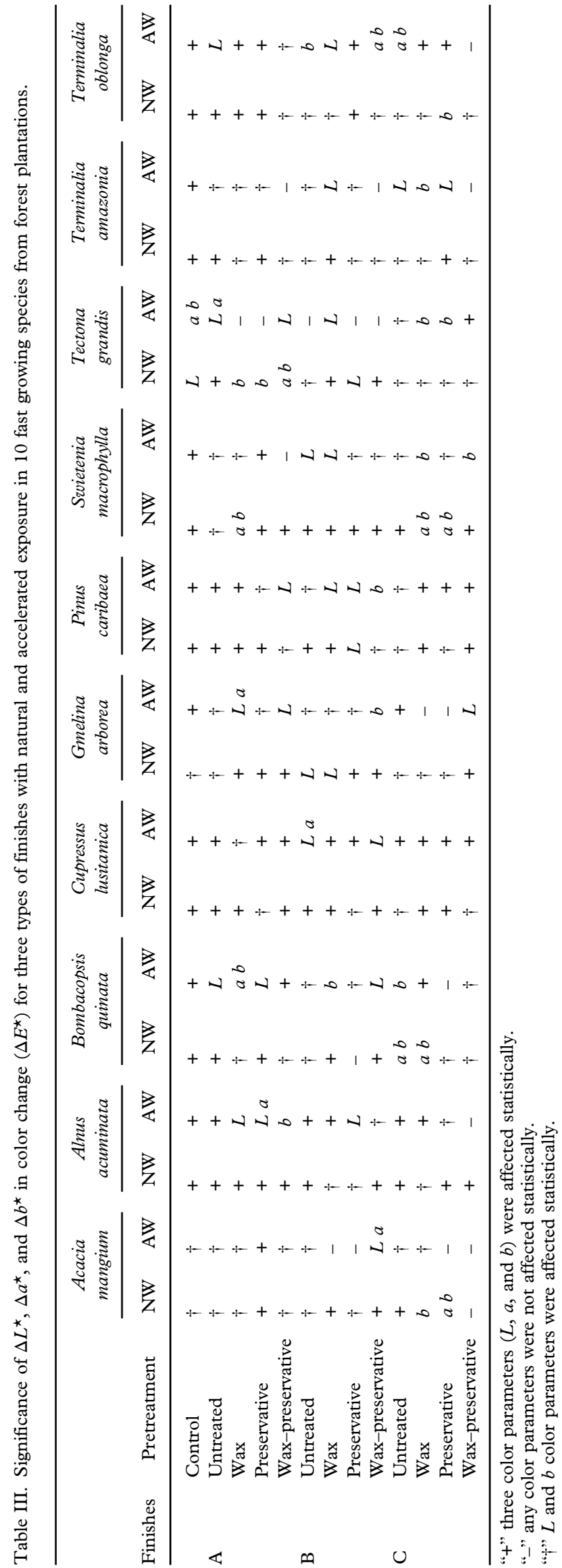


6. The treatments in which $a^{\star}$ and $b^{\star}$ affected $\Delta E^{\star}$ significantly, $L^{\star}$ did not affect $\Delta E^{\star}$, for example in $A$. mangium in NW in C-preservative.

7. In C. lusitanica wood, regardless of the type of finish, the $\Delta E^{\star}$ was significantly affected by the changes in $L^{\star}, a^{\star}$, and $b^{\star}$.

8. For NW, as expected, the $\Delta E^{\star}$ was frequently affected by the change in the three color parameters $\left(L^{\star}, a^{\star}\right.$, and $\left.b^{\star}\right)$ in A finishes, for any type of surface treatment, with the exception of $A$. mangium, which was mostly affected by $L^{\star}$ and $b^{\star}$ together.

\section{Surface quality}

According to the surface evaluation, dark and blue stains on the finish appeared in few species and in few treatments. The stains were observed in A. mangium and T. oblonga, in finishes $\mathrm{B}$ and $\mathrm{C}$ in all surface treatments in AW. This flaw also appeared in $P$. caribaea in finish $\mathrm{C}$ with the $\mathrm{C}$-wax and C-preservative treatments. Concerning fungi on the finished surface, it was not observed in the samples of the different species or finishes exposed to AW. In NW, fungi appeared in almost the entire surface of the finish of all the species, except for $A$. mangium, with the B-untreated and B-preservative treatments.

In NW, fungi were not observed in all treatments of $T$. grandis and T. oblonga and P. caribaea in treatments B-untreated and B-preservative (Table IV). Meanwhile, fungi development was an obstacle for an adequate evaluation of surface deterioration in species with light tonalities, such as $A$. acuminata, B. quinata, G. arborea, P. caribaea, and T. oblonga. Last, bubbles were only observed in samples exposed to AW (Table IV), and they were not observed in 2 of the 10 species studied (B. quinata and $G$. arborea), nor were they found in the samples of all species with type A finish, or in $A$. acuminata and $T$. oblonga with B finish. For almost treatments where bubbles were found, they were observed in $100 \%$ of the samples (Table IV).

The evaluation of surface degradation showed that after weathering none of the species with any kind of finish or pretreatment presented the irregular type of flaw or mosaic flaw. Next, the SQI, in which irregular flaw, long and short lines, and switch flaw were evaluated together, showed, as expected, low values in the samples exposed to NW for almost of the species, except in B. quinata, G. arborea, $P$. caribaea, and T. oblonga with finishes B and C (Figure 4c, 4e, 4f, and 4h), for which the SQI was higher for NW than for AW.

The lowest SQI was found in the different types of finishes of all the species in NW and with finish B in
A. acuminata in NW (Figure 4a). For $A$. acuminata, B. quinata, G. arborea, P. caribaea, and T. oblonga, finish A presented lower values than finishes B and $C$ in the different surface treatments (Figure $4 b, 4 c$, 4e, 4f, and 4j). C. lusitanica, S. macrophylla, $T$. grandis, and T. amazonia, did not show a clear trend in the SQI behavior of the finishes, that was high for some finishes and low for others. The AW analysis found the lowest index in finishes $\mathrm{A}$ in $C$. lusitanica, T. amazonia, and T. oblonga (Figure 4d, $4 \mathrm{i}$, and $4 \mathrm{j}$ ), while the highest SQI value was found in B. quinata, G. arborea, and P. caribaea in finish A (Figure 4c). For $A$. mangium the highest SQI were found in surfaces treated with preservative in any of the finishes (Figure 4a). In $A$. acuminata, again the surfaces treated with preservative and preservativewax in the three types of finishes used, presented the highest SQI. Finish B in S. macrophylla and $T$. grandis presented the highest SQI values (Figure $4 \mathrm{~g}$ and $4 \mathrm{~h}$ ).

\section{Discussion}

Initial color

The positive values found in the initial color of the finishes of the different woods are produced by the combination of white $\left(L^{\star}\right)$, red $\left(a^{\star}\right)$, and yellow $\left(b^{\star}\right)$ tonalities, which reflect the natural color of the wood, since these pretreatments and finishes are almost transparent (Table II). The combination of whites, reds, and yellows is a characteristic pattern of tropical woods (Nishino et al. 1998, Valverde and Moya 2014).

The high color variation of tropical woods is attributable to the variation of the different parameters. The most influencing parameter is luminosity $\left(L^{\star}\right)$. According to this variation, two groups can be established: species with $L^{\star}>54$ and species with $L^{\star}<54$ (Nishino et al. 1998). The previous affirmation agrees with the findings for the species studied, since two groups of color were found: a first group including $A$. mangium, $S$. macrophylla, and T. grandis, with values of $L^{\star}<54$ (Figure $1 \mathrm{a}, 1 \mathrm{~g}$, and 1h), are classified as dark colored and a second group including $A$. acuminata, B. quinata, C. lusitanica, G. arborea, P. caribaea, T. amazonia, and T. oblonga (Figure $1 \mathrm{~b}-1 \mathrm{f}$ and $1 \mathrm{i}-1 \mathrm{j}$ ), with values of $L^{\star}>54$, are classified as light colored.

The application of polyurethane finishes and waxes caused variations in the parameters $\left(L^{\star}, a^{\star}\right.$, and $\left.b^{\star}\right)$ and in $\Delta E^{\star}$ in relation with the natural color of the wood (Figure 2 and Table II). The active components of each finish (resins and oils in finish $\mathrm{A}$, and urethane prepolymer in the polyurethane in finishes $\mathrm{B}$ and $\mathrm{C}$ ), together with the lignin stabilizing 
Table IV. Percentage of pieces with fungi in natural exposure, and with bubbles in accelerated exposure obtained for 10 tropical species from plantations, with three types of finish and various treatments.

\begin{tabular}{|c|c|c|c|c|c|c|c|c|c|c|c|c|c|c|c|c|c|c|c|c|c|}
\hline \multirow[b]{3}{*}{ Finishes } & \multirow[b]{3}{*}{ Pretreatment } & \multicolumn{10}{|c|}{ Presence of fungi in natural exposure } & \multicolumn{10}{|c|}{ Presence of bubbles in accelerated exposure } \\
\hline & & 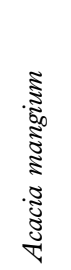 & 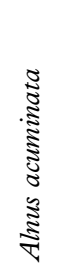 & 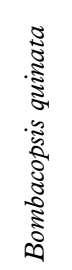 & 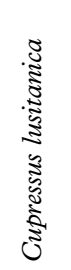 & 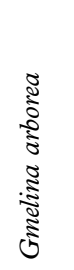 & 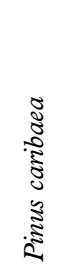 & 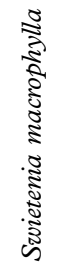 & 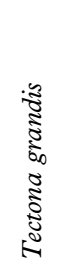 & 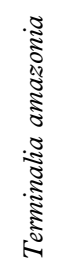 & 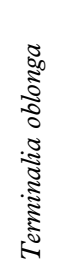 & 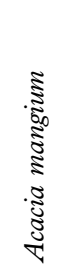 & 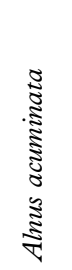 & 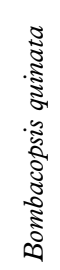 & 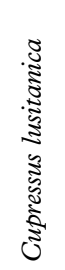 & 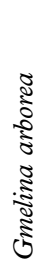 & 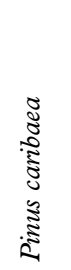 & 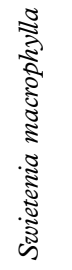 & 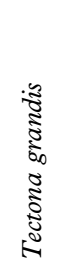 & 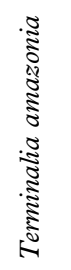 & 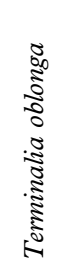 \\
\hline & & & & & & & & & & & & & & & & & & & & & \\
\hline & Conrtol & 100 & 100 & 100 & 100 & 100 & 100 & 100 & 100 & 100 & 100 & - & - & - & - & - & - & - & - & - & - \\
\hline \multirow[t]{4}{*}{ A } & Untreated & - & 100 & 100 & 100 & 100 & 100 & 100 & 100 & 100 & 100 & - & - & - & - & - & - & - & - & - & - \\
\hline & Wax & - & 100 & 100 & 100 & 100 & 100 & 100 & 100 & 100 & 100 & - & - & - & - & - & - & - & - & - & - \\
\hline & Preservative & - & 100 & 100 & 100 & 100 & 100 & 100 & 100 & 100 & 100 & - & - & - & - & - & - & - & - & - & - \\
\hline & Wax-preservative & - & 100 & 100 & 100 & 100 & 100 & 100 & 100 & 100 & 100 & - & - & - & - & - & - & - & - & - & - \\
\hline \multirow[t]{4}{*}{ B } & Untreated & 50 & 100 & 50 & 100 & 100 & - & 100 & 100 & 100 & 100 & 100 & - & - & 100 & - & 25 & 75 & 100 & 100 & - \\
\hline & Wax & - & 100 & 100 & 100 & 100 & 75 & 100 & 100 & 100 & 100 & 100 & - & - & 50 & - & 100 & 100 & 100 & 100 & - \\
\hline & Preservative & 75 & 100 & 100 & 100 & 100 & - & 100 & 100 & 100 & 100 & 100 & - & - & 50 & - & 50 & - & 100 & 74 & - \\
\hline & Wax-preservative & - & 100 & 100 & 100 & 100 & 100 & 100 & 100 & 100 & 100 & 100 & - & - & 25 & - & 50 & 100 & 100 & 100 & - \\
\hline \multirow[t]{4}{*}{$\mathrm{C}$} & Untreated & - & 100 & 100 & 100 & 100 & 100 & 100 & - & 100 & - & 100 & 100 & - & 100 & - & 100 & 100 & 50 & - & 100 \\
\hline & Wax & - & 100 & 100 & 75 & 100 & 100 & 100 & - & 100 & - & 100 & 100 & - & 100 & - & 100 & 75 & 50 & - & 100 \\
\hline & Preservative & - & - & 100 & 100 & 100 & 100 & - & - & 100 & - & 100 & 100 & - & 100 & - & 100 & 100 & 25 & - & 100 \\
\hline & Wax-preservative & - & - & 100 & 75 & 100 & 100 & - & - & 100 & - & 100 & 100 & - & 100 & - & 100 & 100 & 100 & - & 100 \\
\hline
\end{tabular}

"-" indicates that no fungi or bubbles were observed with the respective species and treatment. 
C. Salas et al.
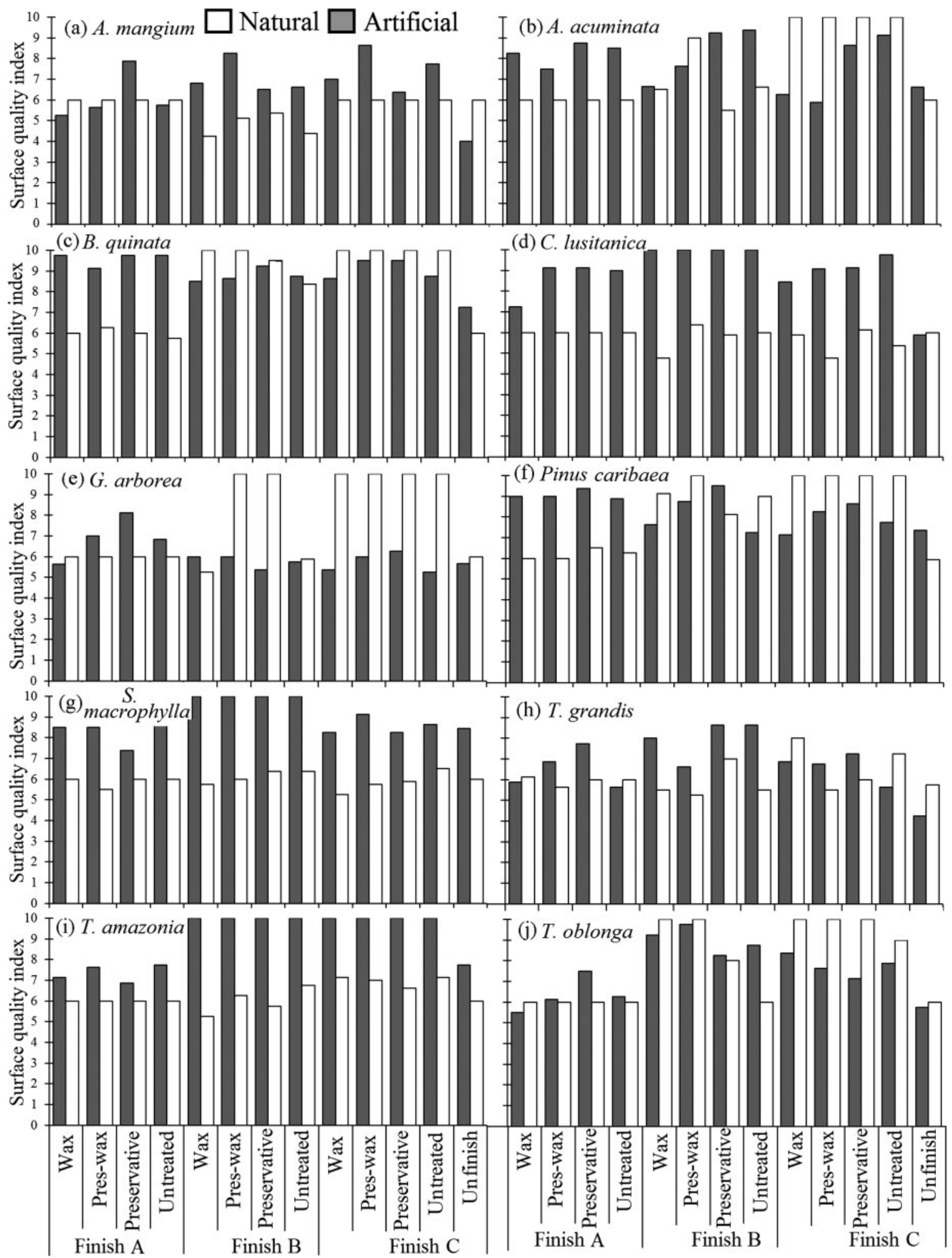

Figure 4. SQI of 10 tropical plantation species exposed to NW and to accelerated weathering with three types of finish and various treatments.

compounds, UV light absorbents, and antioxidant agents, react chemically with the lignin, cellulose, hemicellulose, and extractives that are present in the wood (George et al. 2005, Williams 2005, Schaller and Rogez 2007); the resulting chemical interaction between the wood and finish, causes a change of 
magnitude of the $L^{\star}, a^{\star}$, and $b^{\star}$ parameters (Figure 2), and therefore a variation in the $\Delta E^{\star}$ (Table II), in all of the species studied.

Similarly, the chemical composition of the different types of finish caused interactions with wood components (Temiz et al. 2007), and as a result in some species or surface treatment, one of the three parameters was not significantly affected, as in B. quinata and P. caribaea with finishes B and C. In this case the parameter $a^{\star}$ was not significantly influenced (Figure $2 \mathrm{~m}$ and $2 \mathrm{p}$ ).

Although some parameters did not change in the species (Figure 2), $\Delta E^{\star}$ is in almost cases higher than 12 units (Table II), that is considered as a total change in color (Nishino et al. 1998). Another important aspect regarding the values of $\Delta \mathrm{E}^{\star}$ is that these were different in all species. However, the treatments applied with finish A presented the lowest values (Table II), followed by $\mathrm{C}$ and $\mathrm{B}$. Such result was expected since finish A presents a cedar tonality, while for finishes $\mathrm{B}$ and $\mathrm{C}$ the formulation was $100 \%$ transparent (Table I). Due to this composition, the application of finish A tends to produce a darker color than the one produced by finishes $\mathrm{B}$ and $\mathrm{C}$, which cause higher values of $\Delta E^{\star}$ (higher color change) in woods with high values of $L^{\star}$ or light colored woods (A. acuminata, B. quinata, C. lusitanica, G. arborea, $P$. caribaea, T. amazonia, and T. oblonga). Nevertheless, the woods with the lowest values of $L^{\star}$, called dark woods (A. mangium, S. macrophylla, and $T$. grandis), present a lower $\Delta E^{\star}$.

\section{Color change after exposure}

Regarding the variation of $\Delta E^{\star}$ between $\mathrm{NW}$ and AW after weathering, the highest values were obtained in NW. In fact, $\Delta E^{\star}$ showed values above 12 in all cases, regardless of the species or finish (Figure 2), that means a complete change of color. This variation between the two weathering conditions is attributable to the fact that with NW there is constant variability of solar radiation (different wave lengths applied: NW produces higher wave length), humidity, rainfall, pollution, and biotic agents that accelerate the color degradation process, while with AW those conditions are controlled, and the influence comes mainly from UV rays (George et al. 2005, Sivrikaya et al. 2010). In this regard, Creemers et al. (2002) pointed out the difficulty of reproducing the natural environmental conditions in an artificial test inside a chamber. Because of the adverse conditions present in the $\mathrm{NW}$, the $\Delta E^{\star}$ is over 12 (Figure 2), and there is a total change in color of the wood (Cui et al. 2004).
The change of color of the finishes after weathering, in both NW and AW (Figure 2), may be explained by the processes of photodegradation of the finish in outdoor conditions (George et al. 2005, Deka et al. 2008). Even if the wood is protected, these weather conditions influence the color of the wood surface. First, the degradation of lignin in the wood begins, due to UV light absorption through the finish (Creemers et al. 2002, George et al. 2005), causing the decomposition of the methoxyl groups and the formation of carbonyl and carboxyl chromoformic groups (George et al. 2005, Deka et al. 2008), as well as the degradation of polyphenolic extractives by the UV light (Pandey 2005b). The loss of the lignin and extractives in wood produces a grayish coloration, thus leading to a reduction of $L^{\star}$. The previous result was confirmed for all species and types of finishing, since the $L^{\star}$ parameter affected the $\Delta E^{\star}$ value significantly (Table III).

Last, the variations of $\Delta E^{\star}$ in the different species (Figure 3) are attributable to the variations in the chemical compounds, mainly the extractives present in each wood type (Chung-Yun and Mon-Lin 1988), and its capacity of interaction with the finish (Petric et al. 2004, Pandey 2005b). The species-finish interaction in $A$. mangium and $T$. grandis (classified as dark colored woods) was probably better in NW, showing lower values of $\Delta E^{\star}$ (Figure $3 \mathrm{a}$ and $3 \mathrm{~h}$ ). On the contrary, $A$. acuminata, $C$. lusitanica, $G$. arborea, $P$. caribaea, T. amazonia, and $T$. oblonga, with values of $L^{\star}$ above 54, and listed as light colored woods, presented less wood-finish interaction, which resulted in higher variations of $\Delta E^{\star}$ (Figure $3 \mathrm{~b}, 3 \mathrm{~d}-3 \mathrm{~g}, 3 \mathrm{i}$, and $3 j$ ). However, the high values of $\Delta E^{\star}$ in B. quinata, which is lighter in color, and the lower values of $\Delta E^{\star}$ in $S$. macrophylla, which is darker in color (Figure $3 \mathrm{c}$ and $3 \mathrm{~g}$ ), do not show the same behavior as the rest of the species. That is to say, high values of color change $\Delta E^{\star}$ in light colored and low values of $\Delta E^{\star}$ in dark color. Figures 5 and 6 show wood color change after NW and AW, respectively, in all species and it can be observed that dark species were less affected, but in light colored species, the color change was severe (Figures 5 and 6). Such results indicate that the effects of the extractives on these species are different from the effect on other species. For example, the acetylation - which may vary among species - of $\mathrm{OH}$ groups, is a strategy used in the chemical formulation of finishes to stop photodegradation (George et al. 2005).

On the other hand, the trend of the condition of exposure was not defined, with light colored woods producing high values of $\Delta E^{\star}$, and dark colored woods producing low values of $\Delta E^{\star}$. In both types of exposures some light colored species, such as A. acuminata, B. quinata, and G. melina, presented 


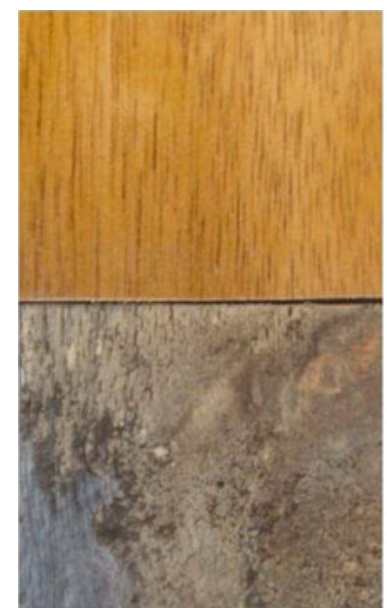

Acacia magium

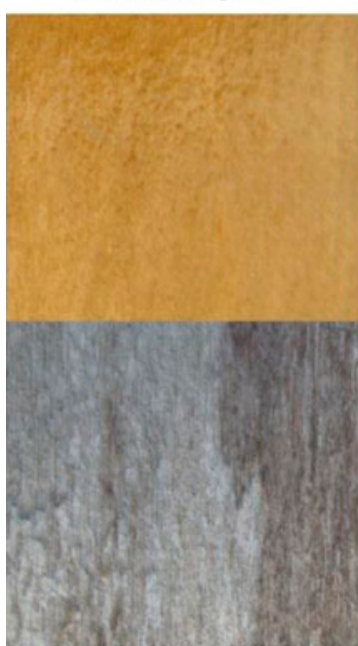

Alnus acuminata

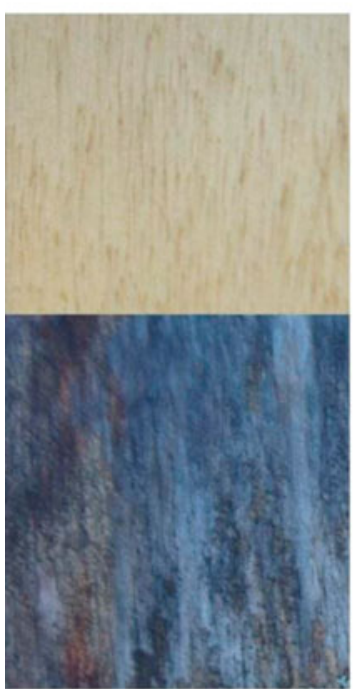

Gmelina arborea

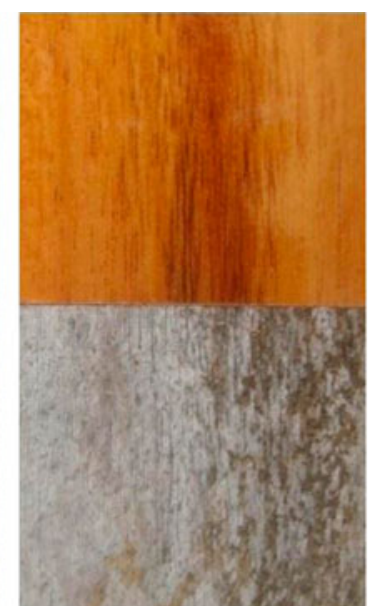

Swietenia macrophylla

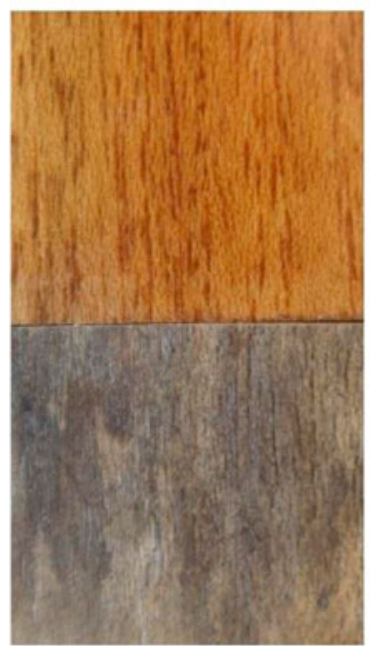

Bombacopsis quinata

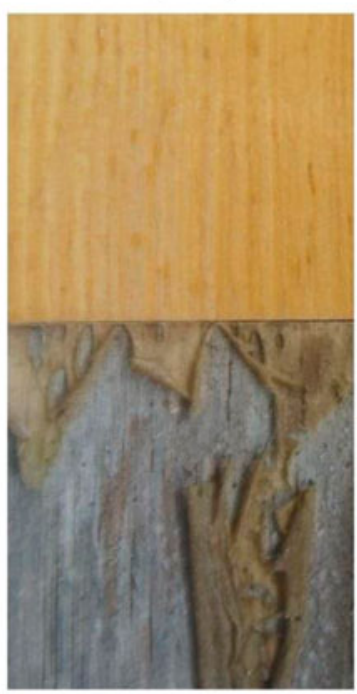

Pinus cariabaea

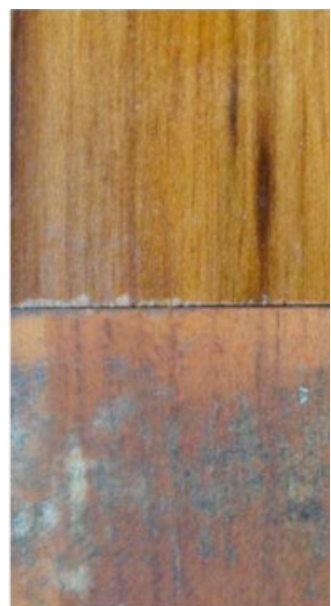

Tectona grandis

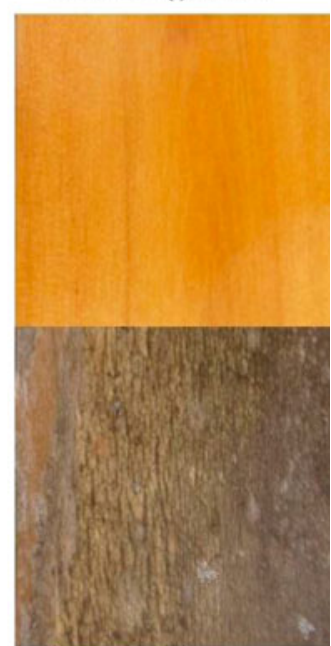

Cupressus lusitanica

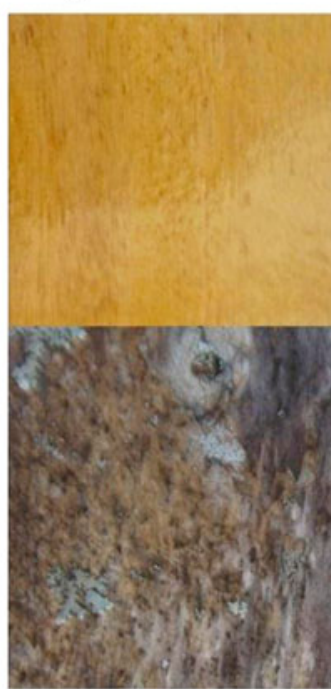

Terminalia amazonia

Figure 5. Surface quality before and after weathering of 10 tropical plantation species exposed to NW.

high values of $\Delta E^{\star}$ (Figure $3 \mathrm{a}-3 \mathrm{c}$ and $3 \mathrm{e}$ ). Such results indicate that the performance of the finish in an artificial condition does not totally reflect the result obtained with NW.
Although the purpose of the finish is to protect the natural wood color (Williams et al. 1999), such protection becomes less effective with time, due to the loss in effectiveness of the lignin stabilizers and 


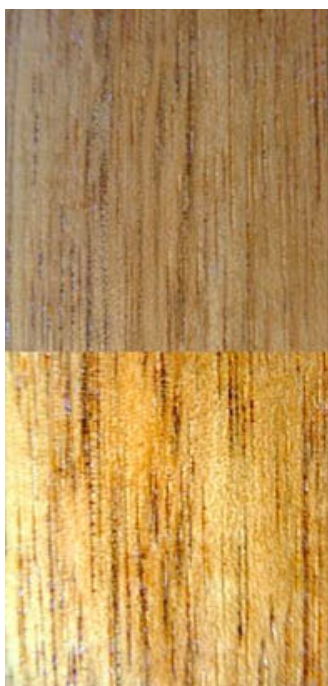

Acacia mangium

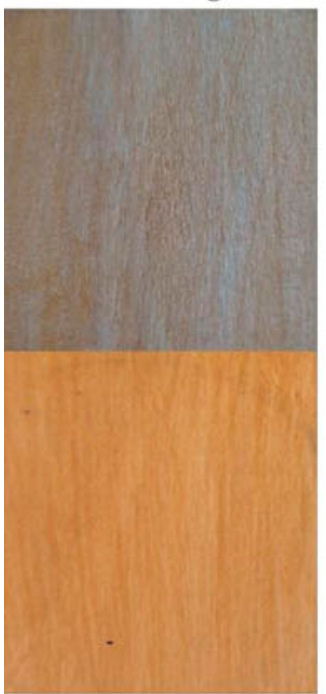

Alnus acuminata

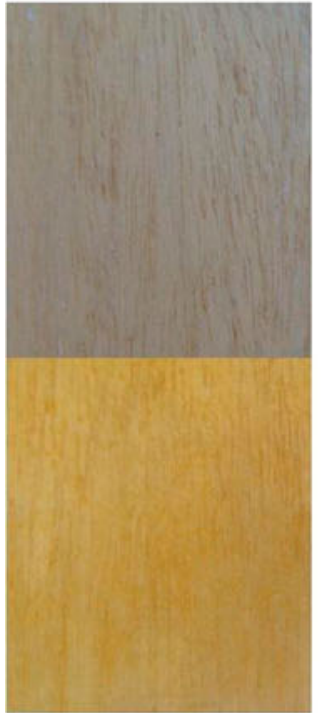

Gmelina arborea

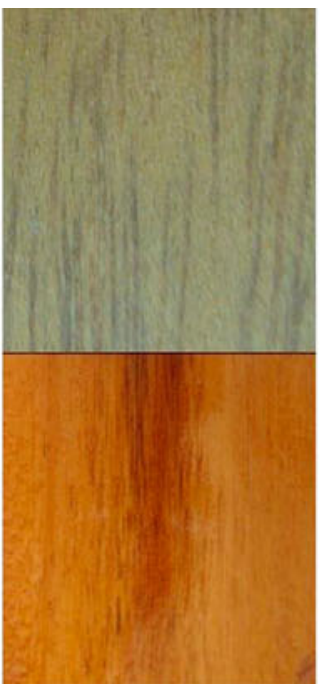

Swietenia macrophylla

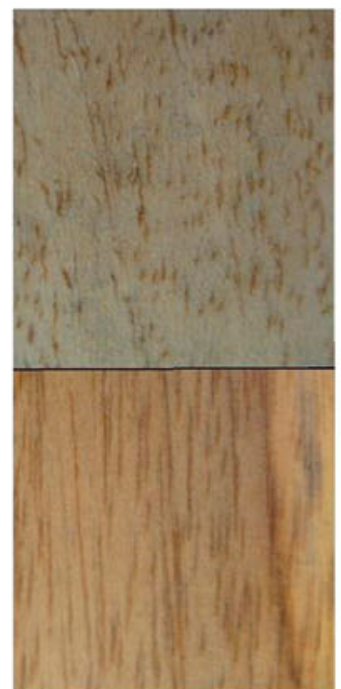

Bombacopsis quinata

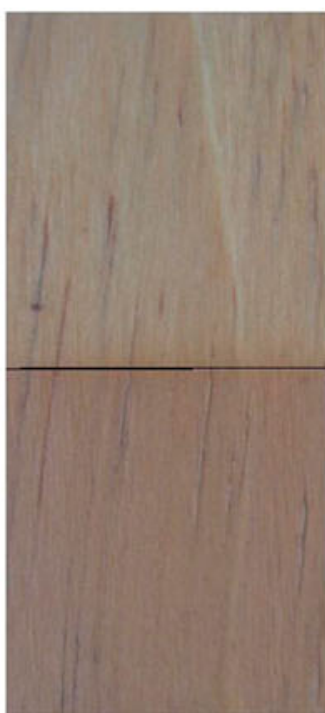

Pinus cariabaea

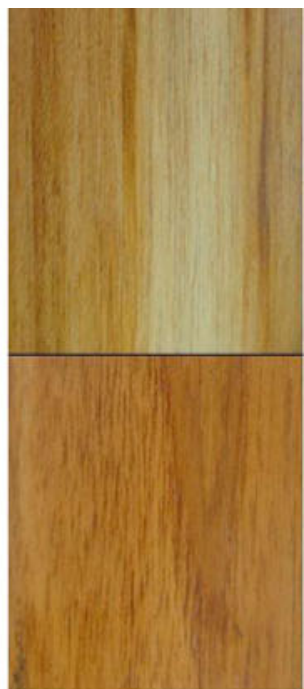

Tectona grandis

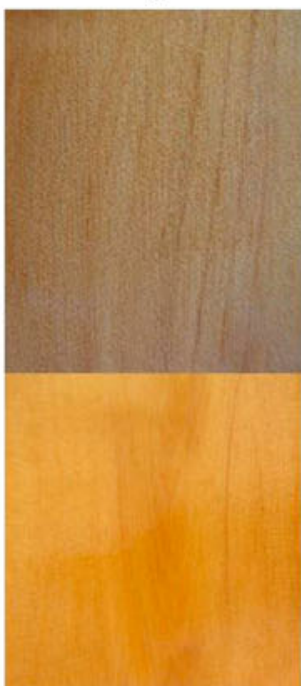

Cupressus lusitanica

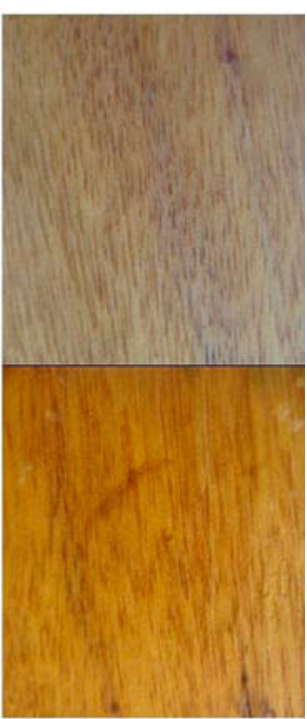

Terminalia amazonia

Figure 6. Surface quality before and after weathering of 10 tropical plantation species exposed to AW. 
the UV filters of the finishes (George et al. 2005), hence the loss of the color. Based on the above, after 500 days exposure to $\mathrm{NW}$, the finish had probably lost its effectiveness to maintain the color (Figure 5), thus indicating that less days can be better to test the effectiveness in tropical conditions. For example, with the 350 days exposure study carried out for $T$. grandis and A. mangium, both species used in this work, it was possible to measure the effectiveness of the finish (Valverde and Moya 2014).

The analysis of the influence of the color parameters on color change $\left(\Delta E^{\star}\right)$ showed that $L^{\star}, a^{\star}$, and $b^{\star}$ have a significant influence on wood that has not received some kind of finish or pretreatment. When a type of finish or pretreatment has been applied, $L^{\star}$ and $b^{\star}$ have the greatest influence upon $\Delta E^{\star}$ (Table III). Such behavior is caused by a chemical modification of the surface due to exposure (Chung-Yun and Mon-Lin 1988, George et al. 2005). The UV rays that enter directly, or are let in by the wood surface pretreatment, produce the decomposition of the lignin methoxyl groups and begin to form carbonyl and carboxyl chromoformic groups, added to the degradation of extractives (George et al. 2005, Deka et al. 2008). Because of the loss of lignin and wood extractives, the wood starts to become grayish. This primarily increases the value of parameter $L^{\star}$ (Gierlinger et al. 2004, Deka et al. 2008), that is negatively correlated with $a^{\star}$ (Moya and Berrocal 2010), thus indirectly affecting the value of $\Delta E^{\star}$. In addition, although the finishes are made with UV light stabilizers and antioxidants to increase resistance to weathering, maintaining the color is impossible (Moya and Berrocal 2010); the parameters of luminosity $\left(L^{\star}\right)$ and the yellows $\left(b^{\star}\right)$ being the most affected. With regard to the reddish parameter $\left(a^{\star}\right)$, it is generally related to the addition of additives to produce darker colors (Jewitt 2000), which is not the case, since the finishes used in the present study are transparent (Table I), so it was expected that this parameter would be unaffected (Table III).

\section{Quality of the surface}

One of the limitations of the AW is that due to high temperature and high UV intensity, the development of stains and fungi is impeded (Ghost et al. 2009), whereas with $\mathrm{NW}$, the temperature and relative humidity of tropical conditions help development of stain and fungi (Valverde and Moya 2014). This explains why in NW fungi and stains were observed in almost species and treatments of surface (Table IV). However, this defect on the surface of the finish could be washed away with a bleach solution (Williams 2005). Bubbles, on the other hand, were only observed in AW in the polyurethane finishes (Table IV). This defect is due to the application of high temperature cycles and water vapor condensation in AW, which slowly break the surface tension of the finish, causing bubbles to be formed by the water trapped in the bottom of the finish (Jewitt 2000).

In relation to the quality of the finish surface, the absence of irregular and mosaic, coincides with the results found for other tropical species studied in Costa Rica (Valverde and Moya 2014). Such defects usually appear when the finish has been exposed for long periods of time and presents poor adherence to the substrate (Williams and Feist 2001).

Exposure to UV light, with variations of temperature and relative humidity, together with exposure to water, generate degradation and erosion processes in the wood which cause defects (long and short lines and switch flaw) on the finish surface, thus reducing the quality of the wood surface (Williams and Feist 2001). However, despite this degradation of the finishes, the SQI presented was higher than for wood without treatment (Figure 4), which is explained by the fact that the finish stops the degradation of lignin (Williams 2005) and the loss of extractives and cellulose in the wood surface (Creemers et al. 2002), if it is not adequately protected (Williams and Feist 2001).

The high SQI obtained with polyurethane finishes (B and C) in NW is attributable to the hard-resistant film this type of finish forms and its good interaction with the wood, whereas with the wax type finish A, probably of low resistance to surface tension and poor response to environment, the formation of flaws and cracks (splits) on the finish is propitiated, which is reflected in the SQI (Evans et al. 2008).

The low SQI found in NW was to be expected since, as commented above, the conditions of UV radiation, temperature, water, and variations of those for long periods of time, causes the wood surface tension to rise with the additional degradation of the finish (Tolvaj and Mitsui 2005). The entrance of biotic factors in NW (Table IV) also accelerates the deterioration processes (Williams and Feist 2001, Evans et al. 2008). However, the SQI found in $A$. acuminata, B. quinata, G. arborea, $P$. caribaea, and $T$. oblonga, with finishes B and C (Figure 4c, 4e, 4f, and 4h), was higher in NW than in AW. However, this result must be taken carefully since the defects evaluated could not be adequately observed in these species at the end of the 400 hours exposure. Irregular flaws, long and short lines, and switch flaws are difficult to evaluate in the mentioned species in such conditions, due to their light color. 


\section{Conclusions}

The initial color of the wood from plantation species was different in each species. The lowest values of the $L^{\star}$ parameter, under 54, were observed in A. mangium, S. macrophylla, and T. grandis and they were classified as dark colored woods. Species with higher values of $L^{\star}$, above 54, were cataloged as light colored woods. The finishes changed the values of the color parameters, $L^{\star}$ decreased and $a^{\star}$ and $b^{\star}$ increased for all species. Because of these changes in the parameters, the change of color was cataloged as total change. The greatest change though, was found in the wax finish, because of its cedar pigmentation.

Color change $\left(\Delta E^{\star}\right)$ after weathering in wood with any finish or pretreatment was influenced significantly by $L^{\star}, a^{\star}$, and $b^{\star}$, while if finish or pretreatment has been applied, $L^{\star}$ and $b^{\star}$ are the main parameters influencing $\Delta E^{\star}$ in the 10 tropical species studied. However, it was found that wood color change after weathering and was less affected in species with dark colored wood (A. mangium, $S$. macrophylla, and T. grandis), but in light colored species (A. acuminata, B. quinata, C. lusitanica, G. arborea, P. caribaea, T. amazonia, and T. oblonga), the color change was severe. Dark woods tended to lighten and light woods tended to darken.

Regarding the evaluation of defects, the stains on the finishes were only present in a few species (A. mangium, P. caribaea, and T. oblonga) and few treatments. No fungi were observed on the finished surface in the different species, or finishes exposed to AW, whereas in NW fungi were observed in almost the totality of the species, except for A. mangium. Bubbles were not observed in natural exposure in any of the finishes, except for polyurethane type finishes. No bubbles were found with wax finishes. The evaluation of the SQI, as expected, showed low values of SQI for the NW samples, except for B. quinata, G. arborea, P. caribaea, and T. oblonga with finishes $\mathrm{B}$ and $\mathrm{C}$.

\section{Acknowledgments}

The authors wish to thank The Vicerrectoria de Investigación y Extensión of the Instituto Tecnológico de Costa Rica for its financial support and Grupo Kativo S.A. for their support with finishes.

\section{References}

Ahajji, A., Diouf, P. N., Aloui, F., Elbakali, I., Perrin, D., Merlin, A. and George, B. (2009) Influence of heat treatment on antioxidant properties and colour stability of beech and spruce wood and their extractives. Wood Science and Technology, 43(1-2), 69-83.
ASTM (2013a) Standard Practice for Operating Fluorescent Light Apparatus for UV Exposure of Nonmetallic Material (G 154-98) (Pennsylvania: Book of Standards), 12 p.

ASTM (2013b) Standard Practice for Calculation of Color Tolerances and Color Differences from Instrumentally Measured Color Coordinates (D 2244-02) (Pennsylvania: Book of Standards), 8 p.

ASTM (2013c) Standard Test Method for Evaluating Degree of Checking of Exterior Paints (D 660-93) (Pennsylvania: Book of Standards), $4 \mathrm{p}$.

Chung-Yun, H. and Mon-Lin, K. (1988) Influence of extractives on wood gluing and finishing - A review. Forest Products fournal, 38(1), 52-56.

Creemers, J., de Meijer, M., Zimmermann, T. and Sell, J. (2002) Influence of climatic factors on the weathering of coated wood. European fournal Forest Products, 60, 411-420.

Cui, W., Kamdem, P. and Rypstra, T. (2004) Diffuse reflectance infrared Fourier transform spectroscopy (DRIFT) and color changes of artificial weathered wood. Wood Fiber and Science, 36, 291-301

Deka, M., Humar, M., Rep, G., Kricej, B., Šentjurc, M. and Petric, M. (2008) Effects of UV light irradiation on colour stability of thermally modified, copper ethanolamine treated and non-modified wood: EPR and DRIFT spectroscopic studies. Wood Science and Technology, 42(1), 5-20.

Evans, P. D., Urban, K. and Chowdhury, M. J. A. (2008) Surface checking of wood is increased by photodegradation caused by ultraviolet and visible light. Wood Science and Technology, 42(3), 251-265.

George, B., Suttie, E., Merlin, A. and Deglise, X. (2005) Photodegradation and photostabilitation of wood - The state of art. Polymer Degradation and Stability, 88(2), 268-274.

Ghost, S. C., Militz, H. and Mai, C. (2009) Natural weathering of scoots pine (Pinus sylvestris L.) boards modified with functionalized commercial silicone emulsions. Bioresources, 4, 659-673.

Gierlinger, N., Jacques, D., Grabner, M., Wimmer, R., Schwanninger, M., Rozenberg, P. and Pâques, L. E. (2004) Colour of larch heartwood and relationships to extractives and brown-rot decay resistance. Trees Structure and Function, $18(1), 102-108$.

Jewitt, J. (2000) Great wood finishes (New York: Taunton Press).

Moya, R. and Berrocal, A. (2010) Wood colour variation in sapwood and heartwood of young trees of Tectona grandis and its relationship with plantation characteristics, site, and decay resistance. Annals of Forest Science, 67(1), 109.

Moya, R. and Muñoz, F. (2010) Physical and mechanical properties of eight species from fast-growth plantation in Costa Rica. Fournal Tropical of Forest Science, 22, 317-328.

Moya, R. and Tenorio, C. (2013) Fuelwood characteristics and its relation with extractives and chemical properties of ten fastgrowth species in Costa Rica. Biomass and Bioenergy, 56, $14-21$.

Moya, R., Urueña, E., Salas, C., Muñoz, F. and Espinoza, O. (2013) Kiln drying behavior of lumber from ten fast-growth plantation species in Costa Rica. Wood Material Science and Engineering, 8(1), 37-45.

Nichols, J. D. and Vanclay, J. K. (2012) Domestication of native tree species for timber plantations: Key insights for tropical island nations. International Forestry Review, 14(4), 402-413.

Nishino, Y., Janin, G., Chanson, B., Détienne, P., Gril, J. and Thibaut, B. (1998) Colorimetry of wood specimens from French Guiana. Fournal of Wood Science, 44(1), 3-8.

Pandey, K. K. (2005a) A note on the influence of extractives on the photo-discoloration and photo-degradation of wood. Polymer Degradation and Stability, 87(2), 375-379. 
Pandey, K. K. (2005b) Study of the effect of photo-irradiation on the surface chemistry of wood. Polymer Degradation and Stability, 90(1), 9-20.

Pastore, T. C. M., Santos, K. O. and Rubim, J. C. (2004) A spectrocolorimetric study on the effect of ultraviolet irradiation of four tropical hardwoods. Bioresource Technology, 93(1), 37-42.

Petit, B. and Montagnini, F. (2004) Growth equations and rotation ages of ten native tree species in mixed and pure plantations in the humid neotropics. Forest Ecology and Management, 199(2-3), 243-257.

Petric, M., Kricej, B., Humar, M., Pavlic, M. and Tomazic, M. (2004) Patination of cherry wood and spruce wood with ethanolamine and surface finishes. Surface Coatings International Part B: Coatings Transactions, 87(3), 195-201.

Schaller, C. and Rogez, D. (2007) New approaches in wood coating stabilization. Fournal of Coatings Technology and Research, 4(4), 401-409.

Schnabel, T., Zimmer, B. and Petutschnigg, A. J. (2009) On the modelling of colour changes of wood surfaces. European Fournal of Wood and Wood Products, 67(2), 141-149.

Sivrikaya, H., Hafizoglu, H., Yasav, A. and Aydemir, D. (2010) Natural weathering of oak (Quercus petrae) and chestnut (Castanea sativa) coated with various finishes. Color Research Application, 36, 1-24.
Temiz, A., Terziev, N., Eikenes, M. and Hafren, J. (2007) Effect of accelerated weathering on surface chemistry of modified wood. Applied Surface Science, 253(12), 5355-5362.

Tolvaj, L. and Mitsui, K. (2005) Light source dependence of the photodegradation of wood. Fournal of Wood Science, 51(5), $468-473$.

Valverde, J. C. and Moya, R. (2014) Correlation and modeling between color variation and quality of the surface between accelerated and natural tropical weathering in Acacia mangium, Cedrela odorata and Tectona grandis wood with two coating. Color Research Application. doi:10.1002/col.21826

Williams, R. S. and Feist, W. C. (2001) Duration of wood preweathering: Effect on the service life of subsequently applied paint. Fournal of Coatings Technology, 73(9), 65-72.

Williams, R. S., Sotos, P. and Feist, W. C. (1999) Evaluation of several finishes on severely weathered wood. Fournal of Coatings Technology, 71(8), 97-102.

Williams, S. (2005) Finishing of wood. In S.Willians (ed.) Handbook of Wood Chemistry and Wood Composites (New York: CRC Press), pp. 115-210.

Zobel, B. and Sprague, J. (1998) Fuvenile Wood in Trees (New York: Springer-Verlag), 425 p. 